\title{
Grape seed proanthocyanidin extract alleviates ouabain-induced vascular remodeling through regulation of endothelial function
}

\author{
XIANGJU LIU ${ }^{1,2}$, JIE QIU ${ }^{1,2}$, SHAOHUA ZHAO ${ }^{1,2}$, BEIAN YOU ${ }^{1,2}$, XIANG JI ${ }^{1,2}$, YAN WANG ${ }^{1,2}$, \\ XIAOPEI CUI ${ }^{1}$, QIAN WANG ${ }^{1}$ and HAIQING GAO ${ }^{1,2}$ \\ ${ }^{1}$ Department of Geriatrics, Shandong University Qilu Hospital, Jinan, Shandong 250012; \\ ${ }^{2}$ Shandong Provincial Key Laboratory of Cardiovascular Proteomics, Jinan, Shandong 250012, P.R. China
}

Received March 29, 2012; Accepted August 1, 2012

DOI: $10.3892 / \mathrm{mmr} .2012 .1026$

\begin{abstract}
Recent studies indicate that chronic ouabain treatment leads to hypertension and hypertensive vascular remodeling. Grape seed proanthocyanidin extract (GSPE) has been reported to be effective in treating arteriosclerosis, while little is known about its effect on systolic blood pressure and vascular remodeling. In this study, the effects of GSPE on systolic blood pressure and vascular remodeling were analyzed by treating ouabain-induced hypertensive rats with GSPE (250 mg/kg $\cdot \mathrm{d})$. The expression of nitric oxide (NO) and endothelin-1 (ET-1) in thoracic aorta was examined by ELISA; the mRNA and protein levels of TGF- $\beta 1$ were detected using real-time PCR and western blotting, respectively. The results showed that the systolic blood pressure was significantly decreased following treatment with GSPE, with blocked vascular remodeling. The ET-1 content was reduced while NO production was increased in the GSPE group, which showed improved vascular endothelial function. Moreover, GSPE also reduced TGF- $\beta 1$ expression in the thoracic aorta, which is a determinant in vascular remodeling. In conclusion, GSPE antagonized ouabain-induced hypertension and vascular remodeling and is recommended as a potential anti-hypertensive agent for patients with hypertensive vascular diseases.
\end{abstract}

\section{Introduction}

Hypertension is a major health problem that leads to a range of diseases. Hypertension is capable of promoting vascular remodeling, which could be the main reason for increased peripheral vascular resistance and high blood pressure levels. Hypertensive vascular remodeling is associated with structural, functional and biochemical adjustments of endothelial

Correspondence to: Professor Haiqing Gao, Department of Geriatrics, Shandong University Qilu Hospital, 107 Wenhua Xi Road, Jinan, Shandong 250012, P.R. China

E-mail: 3x3eyekafi@163.com

Key words: grape seed proanthocyanidin extract, ouabain, rats, hypertension, vascular remodeling cells, and it involves the degradation and reorganization of the extracellular matrix (ECM) scaffold, as well as hypertrophy and hyperplasia of the vascular smooth muscle cells (VSMCs), all of which contribute to a thickened vessel wall and augmented vascular stiffness.

Vascular cells (endothelial cells, smooth muscle cells and fibroblasts) are critical in vascular remodeling, and many studies suggested that the endothelium senses the hemodynamic changes and initiates the reorganization of the preexisting cellular and extracellular components. This remodeling involves cellular proliferation, apoptosis, migration, cell organization and matrix-integrin interactions throughout the layered structure of the vessel (1). Langille and O'Donnell demonstrated that the endothelium, or a substance produced by the endothelium, was essential for remodeling toward a smaller lumen after a long-term flow reduction (2).

The latest in vitro and in vivo studies have demonstrated that the transforming growth factor- $\beta 1$ (TGF- $\beta 1$ ) isoform showed fundamental significance during vascular development, atherogenesis, neointima proliferation and vessel remodeling. The underlying mechanism may be related with its effects on regulating ECM synthesis, cell cycle progression, apoptosis, differentiation and migration (3-5). It has also been proven that gene expression of TGF- $\beta 1$ may be associated with EC remodeling development (6).

Digitalis, which has been used in clinical practice for over 100 years, has a positive inotropic effect in myocardial cells. Ouabain, a digitalis compound, works as an endogenous regulator of blood pressure and $\mathrm{Na}+\mathrm{K}+-\mathrm{ATPase}$ activity (7). Recent observations indicate that chronic ouabain treatment gives rise to hypertension (8) and hypertensive vascular remodeling (9).

The grape seed proanthocyanidin extract (GSPE) has been reported to be effective in treating arteriosclerosis (10), while little is known about its effects on systolic blood pressure and vascular remodeling.

In this study, the effects of GSPE on the blood pressure and vascular remodeling were examined by treating ouabain-induced hypertensive rats with GSPE $(250 \mathrm{mg} / \mathrm{kg} \cdot \mathrm{d})$, in tandem with the measurement of the systolic blood pressure and vascular remodeling parameters. The expression of nitric oxide (NO) and endothelin-1 (ET-1) in the thoracic aorta were examined by ELISA, and the mRNA and protein levels 
of TGF- $\beta 1$ were respectively detected by real-time PCR and western blotting.

\section{Materials and methods}

Animals. A total of 30 male Sprague-Dawley (SD) rats (5-6 weeks old, weighing 180-220 g, supplied by the Experimental Animal Center of Shandong University, China) were housed in a $12: 12$-h light-dark cycle at $24^{\circ} \mathrm{C}$, and had free access to tap water and standard rat chow ad libitum for 7 days to allow for acclimatization prior to entering the study. All protocols were approved by the Institutional Animal Care and Use Committee of the Qilu Hospital, Shandong University.

Treatment. The 30 rats were randomized into three groups, with 10 rats in each group, treated with nitric sodium (NS), ouabain, GSPE and ouabain, respectively, and thus named the NS group, the $\mathrm{O}$ group and the $\mathrm{GO}$ group. Rats in the $\mathrm{O}$ group were administered ouabain (Sigma Chemical Co., St. Louis, MO, USA) at a dose of $27.8 \mu \mathrm{g} \cdot \mathrm{kg}^{-1} \cdot \mathrm{d}^{-1}$ by intraperitoneal (ip) injection in the early morning of each day for 5 consecutive weeks. Rats in the GO group were administered oral GSPE at a dosage of $250 \mathrm{mg}$ / $\mathrm{kg} \cdot \mathrm{d}$, as well as ouabain at the same dose as the $\mathrm{O}$ group. Rats in the NS group were administered $0.9 \%$ saline $(1 \mathrm{ml} \cdot \mathrm{kg}-1 \cdot \mathrm{d}-1)$ ip and $1 \mathrm{ml} 0.9 \%$ NS orally for the same duration.

Systolic blood pressure (SBP) measurement. The SBP of all animals was measured using an indirect tail-cuff plethysmographic (TCP) method with a rat tail BP monitor (RBP-I, Clinical Medicine Institute, Beijing Sino-Japan Friendship Hospital, China). The rats were kept calm and conscious until pulsatory signals from the arteria caudilis were displayed steadily. At least 10 determinations were made on each rat and the mean of 6 readings within a 5-10 $\mathrm{mmHg}$ range was taken as the SBP of the rat (11). The systolic and diastolic blood pressures were measured for $30 \mathrm{~min}$ with a pressure transducer (model 1050BP, UFI, Inc., Morro Bay, CA, USA) and then recorded using an interface and software for computer data acquisition (model MP100A, BIOPAC System, Inc. Santa Barbara, CA, USA). The SBP was measured once a week until the end of the experiment (six times in total).

Tissue collection. Following five weeks of treatment, the rats were sacrificed by decapitation. Thoracic aortas were rapidly excised and dissected. For morphological and immunohistochemical examination, aorta were fixed in buffered $10 \%$ neutral formalin. For electron microscopy, thoracic aorta were trimmed to $1 \times 1 \times 1 \mathrm{~mm}$ and fixed in $2.5 \%$ glutaraldehyde solution. For analysis of TGF- $\beta 1$ expression, the aorta were instantly frozen in liquid nitrogen and maintained at $-80^{\circ} \mathrm{C}$ prior to use.

Hematoxylin and eosin (HE) staining. Specimens of thoracic aorta were fixed into buffered $10 \%$ neutral formalin for $48 \mathrm{~h}$, dehydrated in graded ethanol solutions, and then embedded in paraffin. The paraffin-embedded specimens were sectioned at $5 \mu \mathrm{m}$. The morphological changes were examined by light microscopy following HE staining.

Ultrastructural examination. Thoracic aorta were trimmed into tissue blocks of $1 \mathrm{~mm}^{3}$ on ice and immediately put into the
$2.5 \%$ glutaraldehyde fixation solution at $4^{\circ} \mathrm{C}$ for $2 \mathrm{~h}$ followed by postfixation in $1 \%$ osmium tetroxide (in $0.1 \mathrm{M}$ phosphate buffer) for $2 \mathrm{~h}$ at $4^{\circ} \mathrm{C}$. The samples were then dehydrated in a graded ethanol series with acetone, permeated and embedded in epoxide resin. Semi-thin sections of approximately $75 \mathrm{~nm}$ were prepared, stained with uranyl acetate and lead citrate, and then observed with an $\mathrm{H}-800$ transmission electron microscope (TEM; Hitachi Electronic Instruments, Tokyo, Japan).

ELISA. Animals were treated as above, and thoracic aortas were excised and stored at $-70^{\circ} \mathrm{C}$ until assay. The amount of $\mathrm{NO}$ and ET-1 was measured using a colorimetric method (optical density) after detection of the protein with a kit purchased from Shanghai Jianglaibio Ltd. Co. (Shanghai, China) and Enzo Life Sciences, Inc. (NY, USA), respectively.

Total RNA isolation and cDNA synthesis of TGF- $\beta 1$. Total RNA isolation from tissues was performed with TRIzol reagent (Omega Bio-Tek, Norcross, GA, USA) according to the manufacturer's instructions. All total RNA samples were subjected to DNase I treatment (DNase I; Fermentas, Burlington, ON, Canada) and stored in RNase-free double distilled water at $-80^{\circ} \mathrm{C}$. RNA quantity and purity were determined by spectrophotometry. The integrity of RNA molecules was monitored by $1 \%$ agarose gel electrophoresis, and specimens with well-pronounced rRNA bands were selected for reactions. The first strand of cDNA was synthesized as follows (First Strand cDNA Synthesis kit, Fermentas): a mixture of $1 \mu \mathrm{g}$ of total RNA, $1 \mu \mathrm{l}$ oligo (dT) 18 primer and DEPC-treated water to $12 \mu \mathrm{l}$ was heated for $5 \mathrm{~min}$ at $65^{\circ} \mathrm{C}$ and chilled on ice; then $4 \mu 1$ of $5 \mathrm{x}$ reaction buffer, $1 \mu \mathrm{l}$ of RNase inhibitor (20 U/ $/ 1), 2 \mu \mathrm{l}$ of dNTP mix (10mM) and $1 \mu \mathrm{l}$ of reverse transcriptase $(200 \mathrm{U} / \mu \mathrm{l})$ were added and incubated for $60 \mathrm{~min}$ at $42^{\circ} \mathrm{C}$, followed by $5 \mathrm{~min}$ at $70^{\circ} \mathrm{C}$ to inactivate the reverse transcriptase, and the mixture was then stored at $-20^{\circ} \mathrm{C}$ for mRNA expression analysis.

Real-time quantitative PCR analysis of TGF- $\beta 1$. Real-time quantitative PCR (qPCR) was performed by RealMaster Green (Tiangen, Beijing, China). The total reaction volume was $20 \mu \mathrm{l}$ (1.5 $\mu \mathrm{l}$ of cDNA template, $8 \mu \mathrm{l} 2.5 \mathrm{x}$ real master mix, $1 \mu \mathrm{l} 20 \mathrm{x}$ SYBR solution, $9 \mu \mathrm{l}$ double distilled water and $0.25 \mu \mathrm{l} 5 \mathrm{mM}$ each of the forward and reverse primers). The real-time quantitative PCR program was $95^{\circ} \mathrm{C}$ for $1 \mathrm{~min}$, followed by 35 cycles of $95^{\circ} \mathrm{C}$ for $5 \mathrm{sec}, 58^{\circ} \mathrm{C}$ for $15 \mathrm{sec}$ and $68^{\circ} \mathrm{C}$ for $20 \mathrm{sec}$. Melting curve analysis and $2 \%$ agarose gel electrophoresis were used to confirm the specificity of each product, the efficiency of PCR was determined by analysis of two-fold or five-fold serial dilutions of cDNA and designed to detect all the signals in the spanning region. The efficiencies were close to $100 \%$, allowing the use of the $2^{-\triangle \triangle C T}$ method for calculation of relative gene expression. All qPCR was conducted with negative controls. The mRNA expression levels of TGF- $\beta 1$ in the thoracic aorta were examined by qPCR. Each sample was performed in triplicate and the data were normalized to $\beta$-actin expression. The primer sequences are listed in Table I.

Western blot analysis of TGF- $\beta 1$ protein expression. Total protein was extracted from the frozen thoracic aorta tissues using RIPA lysis buffer (1\% Triton X-100, $1 \%$ deoxycholate, 
Table I. Primer sequences for detection of PCNA mRNA transcripts.

\begin{tabular}{llll}
\hline Gene & \multicolumn{1}{c}{ Sense $\left(5^{\prime}-3^{\prime}\right)$} & Anti-sense (5'-3') & Length (bp) \\
\hline$\beta$-actin & GAAGTGTGACGTTGACAT & ACATCTGCTGGAAGGTG & 245 \\
TGF- $\beta 1$ & AGAAGTCACCCGCGTGCTAAT & CACTGCTTCCCGAATGTCTGA & 144 \\
\hline
\end{tabular}

PCNA, proliferating cell nuclear antigen; TGF- $\beta 1$, transforming growth factor- $\beta 1$.

$0.1 \%$ SDS) and $1 \mathrm{mM}$ PVMF. Following ultrasonication for $5 \mathrm{~min}$, extracts were centrifuged at $12,000 \mathrm{x} \mathrm{g}$ for $15 \mathrm{~min}$ at $4^{\circ} \mathrm{C}$, and the supernatants containing protein were retained. The protein concentrations in the samples were measured with the BCA method (Beyotime ${ }^{\circledR}$ Institute of Biochemistry, China). In total, $50 \mu \mathrm{g}$ of protein samples were resolved by electrophoresis on a $12 \%$ SDS-polyacrylamide gel (Bio-Rad, Hercules, CA, USA). Proteins were transferred onto a polyvinylidene difluoride (PVDF) membrane. After blocking with 5\% skimmed milk/TBST for $1 \mathrm{~h}$, the membranes were incubated overnight with primary antibodies against TGF- $\beta 1$ (mouse monoclonal, 1:250, Abcam $^{\circledR}$, Hong Kong), and then stripped and incubated with the respective peroxidase-conjugated AffiniPure goat anti-rabbit/mouse IgG (1:10000, ZSGB-Bio). The bands were visualized using the enhanced chemiluminescence system (ECL) and analyzed densitometrically using Image J software. In the meantime, PVDF membranes were probed with $\beta$-actin as an internal control to ensure equal loading.

Statistical analysis. All data analyses were performed using SPSS $^{\circledR}$ version 11.5 (SPSS $^{\circledR}$ Inc., Chicago, IL, USA) for Windows ${ }^{\circledR}$. The data were shown as the means \pm SD. An independent sample t-test was used to compare continuous data between the two groups. $\mathrm{P}<0.05$ was considered to indicate a statistically significant difference.

\section{Results}

Blood pressure. Over a 5-week treatment period, the mean SBPs of the three groups were 108.1, 150.3 and $111.8 \mathrm{mmHg}$, respectively. There was no significant difference between the GO group and the control group ( $\mathrm{P}>0.05$; Fig. 1). However, in the $\mathrm{O}$ group, the systolic blood pressure was much higher than that of the GO and NS groups $(\mathrm{P}<0.05)$. At the end of the treatment, no significant difference in body weight among the three groups was observed $(329 \pm 14,335 \pm 9$ and $317 \pm 10 \mathrm{~g}, \mathrm{P}>0.05)$. Fig. 1 shows the changes in SBP in the three experimental groups over a 5-week period. SBP was assessed using the TCP measurements in each group. The blood pressure was the same in each group at the baseline $(\mathrm{P}>0.05)$, However, after 5 weeks, GSPE-treated animals (GO group) showed significantly decreased SBP compared with those in the $\mathrm{O}$ group $(\mathrm{P}<0.01)$.

HE staining of aorta. Fig. 2 shows histological sections of the thoracic aorta stained with HE. The arrangement of the elastic fibers of aortas from rats in the NS group was normal and there was no hyperplasia of collagen in the vessel wall (Fig. 2A). The aortic wall in the $\mathrm{O}$ group rats thickened, with

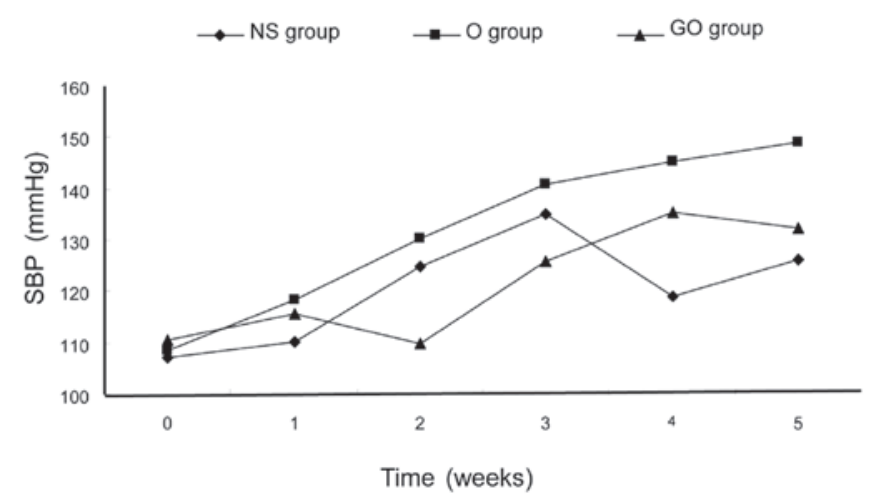

Figure 1. Changes in SBP in the three experimental groups over a 5-week period. SBP, systolic blood pressure; NS group, nitric sodium group; O group, ouabain group; GO group; grape seed proanthocyanidin extract and ouabain group.

hyperplastic collagen fibers in the media and with decreased, disordered and even ruptured elastic fibers (Fig. 2B). Aortic elastic fibers in the GO group were fairly ordered. Collagen fibers were almost normal compared to that in the $\mathrm{O}$ group (Fig. 2C).

Ultrastructural changes of the thoracic aorta. Fig. 3 shows transmission electron photomicrographs of the thoracic aorta in the three groups. The NS group showed a normal tight junction and gap junction structure between the endothelial cells. The majority of heterochromatin was distributed in the circumference of the nucleus. In the $\mathrm{O}$ group, the morphology of endothelial cells in the thoracic aorta changed, with vacuolated cytoplasm and enlarged endoplasmic reticulum, and with no or decreased myofilaments. Nuclear chromatin was dense and observed in lumps of different sizes, which were mainly located in the nuclear membrane. In the GO group, elastin fibers among the endothelial cells increased, with irregular arrangement, and were partly disrupted. Nucleolemma introcession was observed.

Expression of NO and ET-1. Fig. 4 shows the concentration of NO and ET-1 in the thoracic aorta from the three groups. Compared with the NS group, the concentration of NO in the thoracic aorta in the $\mathrm{O}$ group decreased significantly (0.98 vs. $2.57 \mathrm{pg} / \mathrm{mgprot}, \mathrm{P}<0.01$ ); while GSPE treatment increased NO production when comparing the GO group with the $\mathrm{O}$ group ( 2.57 vs. $0.98 \mathrm{pg} / \mathrm{mgprot}, \mathrm{P}<0.01$ ). However, the ET-1 expression increased greatly in the $\mathrm{O}$ group in comparison to that in the NS group (10.33 vs. $5.67 \mathrm{pg} / \mathrm{ml}, \mathrm{P}<0.01)$, which was capable 

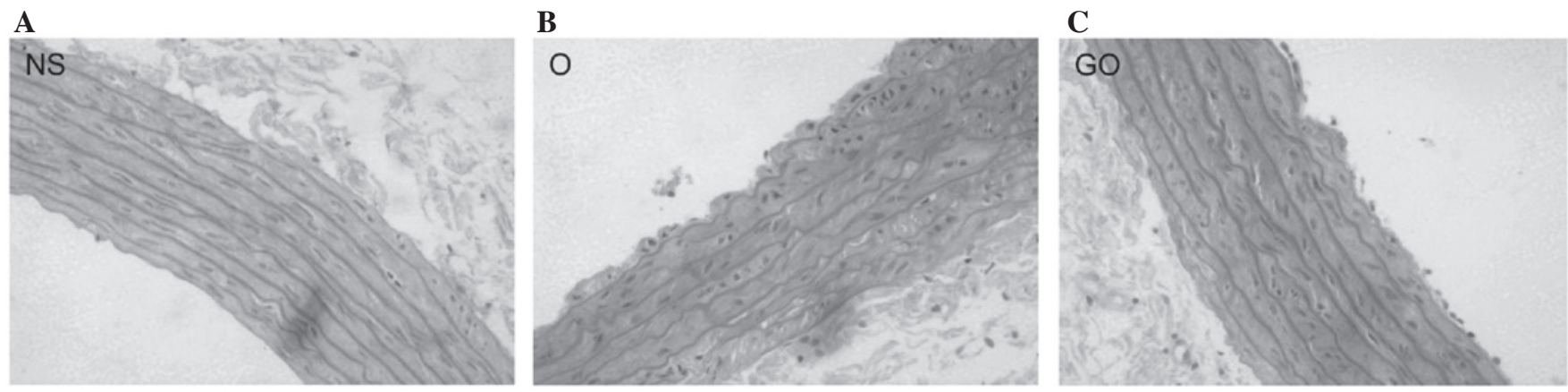

Figure 2. Histological sections of thoracic aorta stained with hematoxylin/eosin in the three groups (magnification, x200). (A) NS group, nitric sodium group; (B) O group, ouabain group; (C) GO group; grape seed proanthocyanidin extract and ouabain group.

A

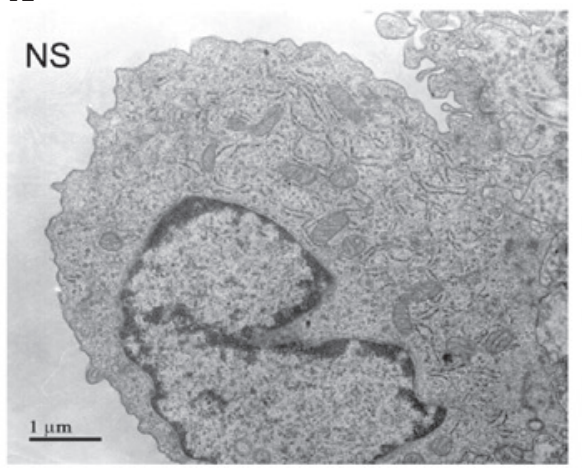

B

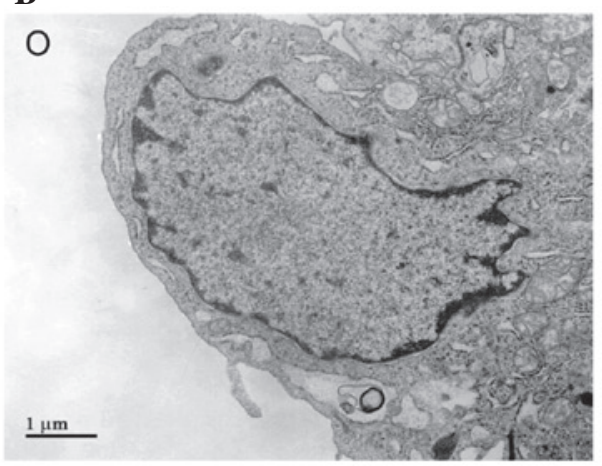

C

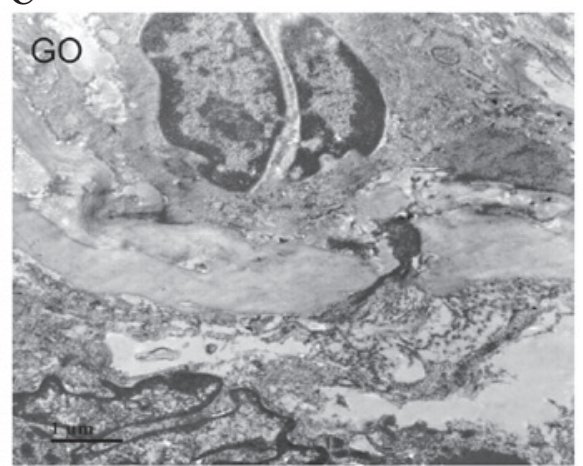

Figure 3. Transmission electron photomicrographs of thoracic aorta in three groups. (A) NS group, nitric sodium group; (B) O group, ouabain group; (C) GO group; grape seed proanthocyanidin extract and ouabain group.

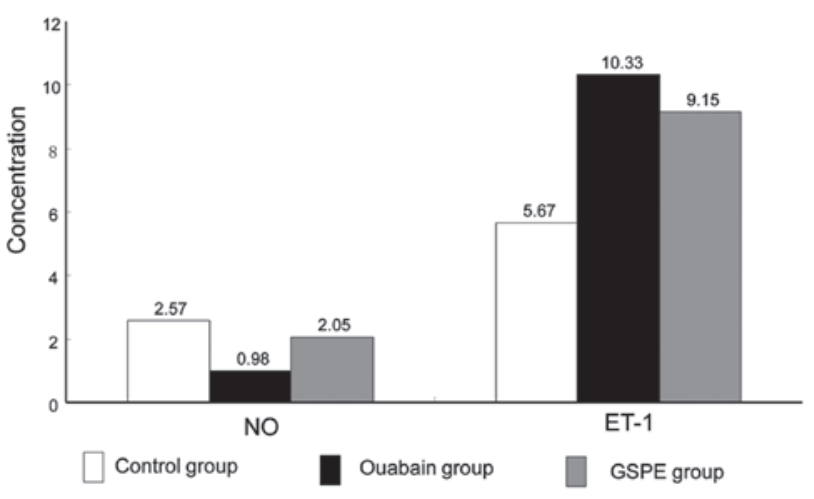

Figure 4. The concentration of NO and ET-1 in the thoracic aorta from the three groups. NO, nitric oxide; ET-1, endothelin-1; GSPE, grape seed proanthocyanidin extract.

of being reversed by GSPE treatment (10.33 vs. $9.15 \mathrm{pg} / \mathrm{ml}$, $\mathrm{P}<0.01)$.

Protein expression of TGF- $\beta 1$. Fig. 5 shows western blot analyses of TGF- $\beta 1$ expression in the three groups. Lysates of the aorta cells treated with or without GSPE were analyzed by western blotting using TGF- $\beta 1$ antibody with $\beta$-actin as an internal control. TGF- $\beta 1$ expression in thoracic aortas in the $\mathrm{O}$ group was significantly increased compared to that in the NS group, and GSPE could decrease the expression of TGF- $\beta 1$ compared with that in the $\mathrm{O}$ group.

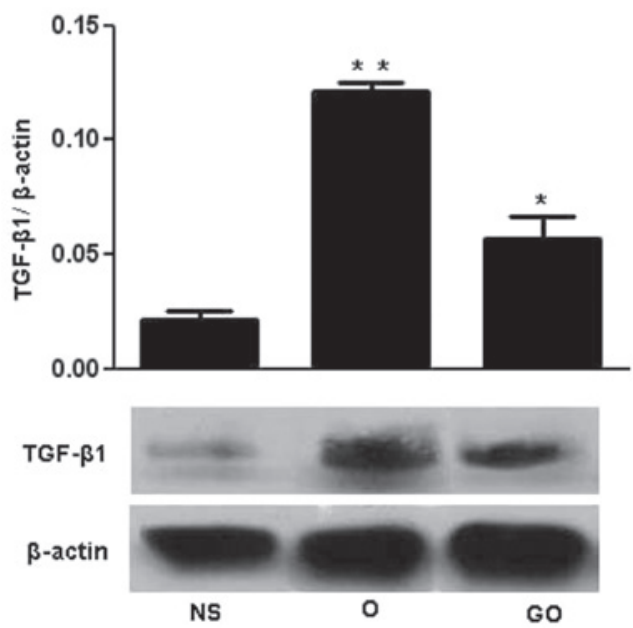

Figure 5. Western blot analysis of TGF- $\beta 1$ expression in the three groups. NS group, nitric sodium group; O group, ouabain group; GO group; grape seed proanthocyanidin extract and ouabain group. ${ }^{*} \mathrm{P}<0.05 ;{ }^{* *} \mathrm{P}<0.01$.

Real-time quantitative PCR analysis of TGF- $\beta 1$. Fig. 6 shows the mRNA expression of TGF- $\beta 1$ in the three groups. Total RNA was isolated from the thoracic aorta in NS, O and GO group rats and subjected to RT-PCR. 18S rRNA gene expression was used as an internal control. The results revealed that the mRNA expression of TGF- $\beta 1$ in the O group was significantly increased compared to that in the NS group, and 


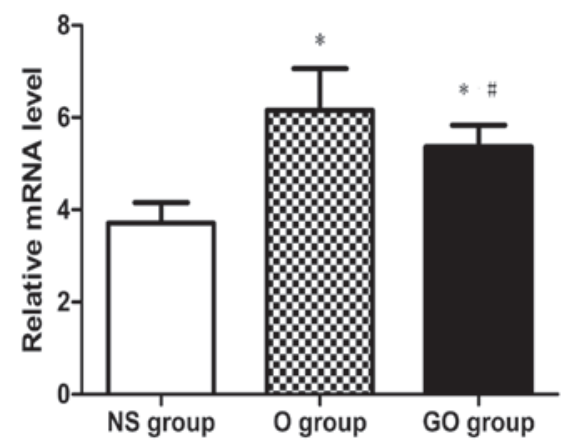

Figure 6. mRNA expression of TGF- $\beta 1$ in three groups. ${ }^{*} \mathrm{P}<0.05$ compared with NS group. ${ }^{*} \mathrm{P}<0.05$ compared with $\mathrm{O}$ group. TGF- $\beta 1$, transforming growth factor- $\beta$ 1; NS group, nitric sodium group; O group, ouabain group; GO group; grape seed proanthocyanidin extract and ouabain group.

GSPE was capable of decreasing the mRNA level of TGF- $\beta 1$ significantly compared with that in the $\mathrm{O}$ group.

\section{Discussion}

Hypertension is a major factor promoting vascular remodeling, which leads to vascular stiffness. Vascular remodeling involves degradation and reorganization of the ECM scaffold, as well as hypertrophy and/or hyperplasia of the vascular smooth muscle cells (VSMCs). It was reported that VSMCs and cardiac hypertrophy were found before high blood pressure in the spontaneously hypertensive rat (SHR) without correlation with blood pressure levels (12).

Digitalis has a positive inotropic effect in myocardial cells, and it has been used in clinical practice for over 100 years. Ouabain, as a digitalis compound, is an endogenous regulator of blood pressure and $\mathrm{Na}+, \mathrm{K}+-\mathrm{ATPase}$ activity (7). Recent studies suggested that chronic ouabain treatment produced hypertension (8) and hypertensive vascular remodeling (9).

Elevated levels of endogenous ouabain or a closely related isomer are involved in rat and human hypertension and in associated cardiovascular complications. Several findings indicated that endogenous ouabain, in addition to directly influencing blood pressure, may be involved in the development of cardiovascular complications (cardiac hypertrophy, heart failure and myocardial infarction) associated with hypertension. Endogenous ouabain may therefore play an important role in vivo as a prohypertrophic hormone and thus may affect cardiovascular function and structure, as it is responsible for cardiac remodeling which contributes to an increased risk of morbid events (8,13-15). Furthermore, exogenous ouabain induced hypertension when chronically administered to normotensive rats $(16,17)$.

Our study showed that a five-week ouabain administration could induce hypertension effectively. Moreover, histological studies showed that ouabain significantly promoted neointimal hyperplasia and VSMC migration when compared with those of the control group.

GSPEs are a group of polyphenolic bioflavonoids exhibiting multiple pharmacological activity and therapeutic potential $(4,18)$. GSPEs have been reported to protect against oxidant injury during ischemia/reperfusion in the rat heart (19-21). Although previous studies have implicated antioxidant effects of GSPE (19-21), none of them revealed the effect of GSPE on endothelial function and hypertension.

In 2009, a study demonstrated that GSPE was capable of lowering blood pressure in subjects with metabolic syndrome and they also found that the phenolic compounds in the extract are absorbed and that its antioxidant properties were capable of reducing the concentration of Ox-LDL in plasma (22).

Endothelium-derived relaxing factors such as NO and prostacyclin usually act in coordination with endotheliumderived constricting factors such as ET-1, thromboxane and serotonin to accommodate changes in the cardiac output and to keep the blood pressure relatively constant. The imbalance of these endothelium-derived factors may elevate vasomotor tone, promote VSMC proliferation and induce vascular remodeling.

NO and ET-1 are key regulators of vasodilatory actions. $\mathrm{NO}$ acts as a second messenger for the actions of a number of growth factors, peptides, coagulation factors and hormones, and is a powerful regulator of vascular function. Endothelium-derived NO is a powerful regulator of vascular function, and it appears that the abnormalities in the production or actions of NO lead to endothelial dysfunction and abnormal vascular remodeling (1). ET-1 is the dominant vasoconstrictive factor. Studies have noted that aortic ET-1 content is significantly increased in DOCA-salt hypertensive rats compared with that in age-matched control rats (23). It has been proposed that this hypertension is due to an imbalance between endogenous vasoconstrictors and the diminished vasodilating effect of NO. Several candidates for endogenous vasoconstrictors that may contribute to sustained hypertension induced by NO blockade have been reported (24-26).

To evaluate the effect of GSPE on endothelial function, ELISA was carried out to examine the concentration of NO and ET-1 in the thoracic aorta.

Through detecting the concentration of NO and ET-1 in the thoracic aorta, we proved that ouabain impaired the balance between NO and ET-1, two major vaso-active substances, which may contribute to damaged endothelial function. GSPE increased NO production and decreased ET-1 expression, resulting in improved endothelial function and better vasodilation.

Improved endothelial function is capable of inhibiting vascular remodeling. Therefore, we subsequently detected another molecule (transforming growth factor- $\beta 1$, TGF- $\beta 1$ ) that is critical in mediating vascular remodeling. The latest in vitro and in vivo studies also demonstrated that TGF- $\beta 1$ is of fundamental importance during vascular development, atherogenesis, neointima proliferation and vessel remodeling. The possible mechanism may be due to its regulation of ECM synthesis, cell cycle progression, apoptosis, differentiation and migration (3-5). A previous study showed that gene expression of TGF- $\beta 1$ may be associated with its development (6). A large number of studies reveal that increased mRNA levels of TGF- $\beta 1$ were observed in myocardial remodeling (27).

In the present study, we proved that ouabain could induce TGF- $\beta 1$ expression at the mRNA and protein level, resulting in vascular remodeling. This result was consistent with the previous reports. GSPE could efficiently inhibit this harmful pathway and therefore block the vascular remodeling induced by ouabain. 
In conclusion, our present study suggested that GSPE could decrease blood pressure efficiently and reverse vascular remodeling in ouabain-induced hypertensive rats. This may be attributed to the regulation of NO and ET-1 balance and the suppression of TGF- $\beta 1$ expression by GSPE. Therefore, GSPE may be a potential anti-hypertensive agent for patients with hypertensive vascular diseases.

\section{Acknowledgements}

This study was supported by a grant from the National Nature Science Foundation of China (30700884) and the Shandong Provincial Scientific and Technological Project (2010GGC10294, BS2009SW015).

\section{References}

1. Rudic RD and Sessa WC: Nitric oxide in endothelial dysfunction and vascular remodeling: clinical correlates and experimental links. Am J Hum Genet 64: 673-677, 1999.

2. Langille BL and O'Donnell F: Reductions in arterial diameter produced by chronic decreases in blood flow are endotheliumdependent. Science 231: 405-407, 1986.

3. Ghosh J, Murphy MO, Turner N, Khwaja N, Halka A, Kielty CM and Walker MG: The role of transforming growth factor beta1 in the vascular system. Cardiovasc Pathol 14: 28-36, 2005.

4. Shao ZH, Becker LB, Vanden Hoek TL, Schumacker PT, Li CQ, Zhao D, Wojcik K, Anderson T, Qin Y, Dey L and Yuan CS: Grape seed proanthocyanidin extract attenuates oxidant injury in cardiomyocytes. Pharmacol Res 47: 463-469, 2003.

5. Heimark, RL, Twardzik DR and Schwartz SM: Inhibition of endothelial regeneration by type-beta transforming growth factor from platelets. Science 233: 1078-1080, 1986.

6. Li RK, Li G, Mickle DA, Weisel RD, Merante F, Luss H, Rao V, Christakis GT and Williams WG: Overexpression of transforming growth factor-betal and insulin-like growth factor-I in patients with idiopathic hypertrophic cardiomyopathy. Circulation 96: 874-881, 1997.

7. Huang BS and FH Leenen: Brain renin-angiotensin system and ouabain-induced sympathetic hyperactivity and hypertension in Wistar rats. Hypertension 34: 107-112, 1999.

8. Hamlyn JM, Hamilton BP and Manunta P: Endogenous ouabain, sodium balance and blood pressure: a review and a hypothesis. J Hypertens 14: 151-167, 1996.

9. Ren YP, Huang RW and Lu ZR: Ouabain at pathological concentrations might induce damage in human vascular endothelial cells. Acta Pharmacol Sin 27: 165-172, 2006.

10. Yamakoshi J, Kataoka S, Koga T and Ariga $T$ : Proanthocyanidin-rich extract from grape seeds attenuates the development of aortic atherosclerosis in cholesterol-fed rabbits. Atherosclerosis 142: 139-149, 1999.

11. Duarte J, Pérez-Palencia R, Vargas F, Ocete MA, Pérez-Vizcaino F, Zarzuelo A and Tamargo J: Antihypertensive effects of the flavonoid quercetin in spontaneously hypertensive rats. Br J Pharmacol 133: 117-124, 2001.
12. Koprdová R, Cebová M And Kristek F. Long-term effect of losartan administration on blood pressure, heart and structure of coronary artery of young spontaneously hypertensive rats. Physiol Res 58: 327-335, 2009.

13. Ferrandi M, Manunta P, Ferrari P and Bianchi G: The endogenous ouabain: molecular basis of its role in hypertension and cardiovascular complications. Front Biosci 10: 2472-2477, 2005.

14. Schoner W and Scheiner-Bobis G: Endogenous cardiac glycosides: hormones using the sodium pump as signal transducer. Semin Nephrol 25: 343-351, 2005.

15. Hamlyn JM, Ringel R, Schaeffer J, Levinson PD, Hamilton BP, Kowarski AA and Blaustein MP: A circulating inhibitor of (Na+ $+\mathrm{K}+$ )ATPase associated with essential hypertension. Nature 300: 650-652, 1982.

16. Manunta P, Rogowski AC, Hamilton BP and Hamlyn JM: Ouabain-induced hypertension in the rat: relationships among plasma and tissue ouabain and blood pressure. J Hypertens 12: 549-560, 1994.

17. Xavier FE, Rossoni LV, Alonso MJ, Balfagón G, Vassallo DV and Salaices M: Ouabain-induced hypertension alters the participation of endothelial factors in alpha-adrenergic responses differently in rat resistance and conductance mesenteric arteries. Br J Pharmacol 143: 215-225, 2004.

18. Bagchi D, Bagchi M, Stohs S, Ray SD, Sen CK and Preuss HG: Cellular protection with proanthocyanidins derived from grape seeds. Ann N Y Acad Sci 957: 260-270, 2002.

19. Sato M, Maulik G, Ray PS, Bagchi D and Das DK: Cardioprotective effects of grape seed proanthocyanidin against ischemic reperfusion injury. J Mol Cell Cardiol 31: 1289-1297, 1999.

20. Sato M, Ray PS, Maulik G, Maulik N, Engelman RM, Bertelli AA, Bertelli A and Das DK: Myocardial protection with red wine extract. J Cardiovasc Pharmacol 35: 263-268, 2000.

21. Facino RM, Carini M, Aldini G, Berti F, Rossoni G, Bombardelli E and Morazzoni P: Diet enriched with procyanidins enhances antioxidant activity and reduces myocardial post-ischaemic damage in rats. Life Sci 64: 627-642, 1999.

22. Sivaprakasapillai B, Edirisinghe I, Randolph J, Steinberg F and Kappagoda T: Effect of grape seed extract on blood pressure in subjects with the metabolic syndrome. Metabolism 58: 1743-1746, 2009.

23. Fujita K, Matsumura Y, Kita S, Miyazaki Y, Hisaki K, Takaoka M and Morimoto S: Role of endothelin-1 and the ETA receptor in the maintenance of deoxycorticosterone acetate-salt-induced hypertension. Br J Pharmacol 114: 925-930, 1995.

24. Matsuoka H, Nishida H, Nomura G, Van Vliet BN and Toshima H: Hypertension induced by nitric oxide synthesis inhibition is renal nerve dependent. Hypertension 23: 971-975, 1994.

25. Pollock DM, Polakowski JS, Divish BJ and Opgenorth TJ: Angiotensin blockade reverses hypertension during long-term nitric oxide synthase inhibition. Hypertension 21: 660-666, 1993.

26. Qiu C, Engels K and Baylis C: Angiotensin II and alpha 1-adrenergic tone in chronic nitric oxide blockade-induced hypertension. Am J Physiol 266: R1470-1476, 1994.

27. Bujak M and Frangogiannis NG: The role of TGF-beta signaling in myocardial infarction and cardiac remodeling. Cardiovasc Res 74: 184-195, 2007. 